\title{
Diagnostic Approach in Perimenopausal Women with Abnormal Uterine Bleeding
}

\author{
${ }^{1}$ Urvashi Verma, ${ }^{2}$ Ruchika Garg, ${ }^{3}$ Shivani Singh, ${ }^{4}$ Poonam Yadav, ${ }^{5}$ Rekha Rani
}

\begin{abstract}
Introduction: Abnormal uterine bleeding (AUB) is very common problem in patient attending outpatient department, especially in perimenopausal group.
\end{abstract}

Objective: To study prevalence of abnormal uterine bleeding and its type in perimenopausal women as well as to compare diagnostic efficacy of ultrasonography, hysteroscopy and histopathology.

Material and method: The study was carried out in Department of Obstetrics and Gynecology, Era Medical College, Lucknow, in 100 patient attending outpatient department with AUB in perimenopausal age group.

Observation: Most of the patients were multiparous, more than $50 \%$ belong to socioeconomic class III and IV and mean age was $43.05 \pm 4.09$ years. Commonest complaint was menorrhagia (45\%) followed by metrorrhagia in $19 \%$ and menometorrhagia in $14 \%$. Majority of patients $(85 \%)$ had uterine volume between 151 and $250 \mathrm{~cm}^{3}$. Only three patient had uterine volume more than $252 \mathrm{~cm}^{3}$. Endometrial hyperplasia was diagnosed in $14 \%$ with ultrasonography, $11 \%$ on hysteroscopy while in $15 \%$ on hystopathological examination.

Conclusion: In perimenopausal women with AUB, ultrasonography should be first investigation because of its freely availability, noninvasiveness and cost effectiveness.

Keywords: Perimenopause, Abnormal uterine bleeding, Hysteroscopy.

How to cite this article: Verma U, Garg R, Singh S, Yadav P, Rani R. J South Asian Feder Menopause Soc 2014;2(1):12-14.

Source of support: Nil

Conflict of interest: None

\section{INTRODUCTION}

In 2001, Stages of reproductive aging workshop (STRAW) perimenopause is defined as the period beginning with menopausal transition and ending 12 months after the last menstrual period. ${ }^{1,2}$ This period may last for many years

\footnotetext{
${ }^{1-5}$ Assistant Professor

1,2,4,5Department of Obstetrics and Gynecology, SN Medical College, Agra, Uttar Pradesh, India

${ }^{3}$ Department of Obstetrics and Gynecology, Era Medical College Lucknow, Uttar Pradesh, India
}

Corresponding Author: Urvashi Verma, Assistant Professor Department of Obstetrics and Gynecology, SN Medical College Agra, Uttar Pradesh, India, e-mail: drurvashiverma@rediffmail.com
(2-8 years). Menstrual irregularity in the form of frequency and volume may occur due to fluctuating hormone levels and can be considered normal and expected but many time uterine as well as adenexal pathology may be there. ${ }^{3}$

Ultrasound is a simple, easily available, affordable and noninvasive diagnostic modality to study endometrial pattern and its thickness. At the same time, adenexal and other uterine pathology like intra mural fibroid can also be detected simultaneously with ultrasonography. ${ }^{4,5}$ For better visualization of endometrium high frequency transducer should be preferred transvaginally. ${ }^{6}$

For histopathological examination aspiration along with currattage with 4 no Karman's cannula is sufficient. Initially, dilatation and curettage (D\&C) was considered gold standard investigation in abnormal uterine bleeding (AUB) cases but being a blind procedure, it has a chance of missing small focal lesion. ${ }^{7-9}$

\section{MATERIAL AND METHOD}

The study was carried out in Department of Obstetrics and Gynecology, Era Medical College, Lucknow, in 100 women in perimenopausal age group (41-51 years). All women underwent for ultrasonography (transvaginal), endometrial histopathology (manual vacuum aspiration method) and hysteroscopy after clinical examination and routine investigations.

\section{OBSERVATIONS}

Thirty-eight percent women were in 40 to 43 years, $41 \%$ in 44 to 47 years while $21 \%$ were in 48 to 51 years (Table 1). Most of women were multiparous having 2 to 4 children, i.e. $53 \%$ (Table 2). Majority of women presented with chief complaint of menorrhagia (45\%) followed by polymenorrhoea (23\%) and metrorrhagia (19\%) (Table 3). Majority (85\%) of women had uterine volume between 150 and $250 \mathrm{~cm}^{3}$.

Endometrial hyperplasia was found in $14 \%$ on ultrasonography, in $11 \%$ on hysteroscopy while in $15 \%$ on histopathology (Tables 4 to 6 ). On analyzing the association between symptomps and endometrial pathologies $77.77 \%$ patient with menorrhagia were found to have no endometrial pathologies while $78.99 \%$ patients of metrorrhagia were found to have endometrial pathologies. 
Table 1: Distribution of cases according to their age

\begin{tabular}{llll}
\hline Sl. no. & Age group & No. of patients & Percentage \\
\hline 1 & 40-43 years & 38 & 38 \\
2 & 44-47 years & 41 & 41 \\
3 & 48-51 years & 21 & 21 \\
\hline
\end{tabular}

Table 3: Distribution of cases according to their symptoms

\begin{tabular}{llll}
\hline SI. no. & Chief complaints & No. of patients & Percentage \\
\hline 1 & Menorrhagia & 40 & 40 \\
2 & Metrorrhagia & 19 & 19 \\
3 & Menometrorrhagia & 12 & 12 \\
4 & Polymenorrhea & 23 & 23 \\
5 & Hypomenorrhea & 4 & 4 \\
6 & Postcoital/other & 2 & 2 \\
\hline Total & & 100 & 100 \\
\hline
\end{tabular}

Table 5: Comparative findings on ultrasound, hysteroscopy and histopathology

\begin{tabular}{llll}
\hline Pathology & Ultrasound & Hysteroscopy & Histopathology \\
\hline Normal & 36 & 50 & 49 \\
$\begin{array}{l}\text { Endometrial } \\
\text { hyperplasia }\end{array}$ & 14 & 11 & 15 \\
$\begin{array}{l}\text { Endometrial } \\
\text { polyp }\end{array}$ & 10 & 13 & 12 \\
$\begin{array}{l}\text { Atrophic } \\
\text { endometrium }\end{array}$ & 5 & 6 & 5 \\
$\begin{array}{l}\text { Endocervival } \\
\text { polyp }\end{array}$ & 2 & 2 & 3 \\
$\begin{array}{l}\text { Submucous } \\
\text { myoma }\end{array}$ & 9 & 10 & 9 \\
$\begin{array}{l}\text { Endometrial } \\
\text { carcinoma }\end{array}$ & - & 1 & 1 \\
$\begin{array}{l}\text { Retained } \\
\text { product of } \\
\text { conception }\end{array}$ & 2 & 5 & 4 \\
$\begin{array}{l}\text { Forgotton IUCD } \\
\text { Adenaxal path, }\end{array}$ & 2 & 2 & - \\
$\begin{array}{l}\text { PID 20 and other } \\
\text { fibroid }\end{array}$ & & - & - \\
\hline
\end{tabular}

\section{DISCUSSION}

Ultrasound diagnosed adenexal pathology in 20 patients of AUB which were not possible with hysteroscope alone. Besides this, simple measurement of endometrial thickness with ultrasound is enough to suggest presence of endometrial pathology. The specificity and positive predictive value of ultrasound was found comparable to hysteroscope, i.e. 95.83 and $95 \%$. On comparison of ultrasound with histopathological examination, the sensitivity and negative predictive value of ultrasound for diagnosing endometrial pathology was 73.07 and $76.66 \%$.

Hysteroscope was found to be more accurate in detecting endometrial polyp, submucous myoma, endocervical polyp and endometrial cancer. Sensitivity and specificity
Table 2: Distribution of cases according to their parity

\begin{tabular}{llll}
\hline Sl. no. & Parity & No. of patients & Percentage \\
\hline 1 & $<2$ & 19 & 19 \\
2 & $2-4$ & 53 & 53 \\
3 & $>4$ & 28 & 28 \\
\hline
\end{tabular}

Table 4: Distribution of cases according to ultrasound findings

\begin{tabular}{llll}
\hline SI. no. & Usg findings & No. of patients & Percentage \\
\hline 1 & Normal & 36 & 36 \\
2 & Submucous myoma & 3 & 3 \\
3 & Endometrial hyperplasia & 14 & 14 \\
4 & Atrophic endometrium & 3 & 3 \\
5 & Endometrial polyp & 9 & 9 \\
6 & Fibroid & 22 & 22 \\
7 & PID & 26 & 26 \\
8 & Forgotten IUCD & 2 & 2 \\
\hline
\end{tabular}

Table 6: Hysteroscopic findings

\begin{tabular}{llll}
\hline Sl. no. & Hysteroscopic findings & No. of patients & Percentage \\
\hline 1 & Normal & 44 & 44 \\
2 & Endometrial hyperplasia & 11 & 11 \\
3 & Endometrial polyp & 13 & 13 \\
4 & Atrophic endometrial & 6 & 6 \\
5 & Endometrial malignancy & 2 & 2 \\
6 & Endocervical polyp & 8 & 8 \\
7 & Submucous myoma & 8 & 8 \\
8 & Retained product & 5 & 5 \\
9 & Forgotton IUCD & 2 & 2 \\
\hline Total & & 100 & 100 \\
\hline
\end{tabular}

of hysteroscopic examination in diagnosing endometrial pathology was found to be 89.79 and $97.56 \%$ while positive and negative predictive values were 97.95 and $90.56 \%$ respectively.

Study by Machado et al in 2005 concluded that endometrial thickness less than $5 \mathrm{~mm}$ did not need D\&C as none of these patients had or malignancy. ${ }^{9}$ The upper limit for normal endometrial thickness is controversial but most studies favored cut off value of $8 \mathrm{~mm} .{ }^{10-12}$

The risk of endometrial cancer is significantly high in patients with complex atypical hyperplasia in comparison to simple hyperplasia. ${ }^{13-15}$

Hystopathological examination especially under hysteroscopic guidence is the gold standard for diagnosis of endometrial pathology. ${ }^{14}$ It diagnosed four cases of endometrial hyperplasia missed by hysteroscopy alone.

\section{CONCLUSION}

In perimenopausal women after clinical examination (speculum and bimanual) and Pap smear, ultrasonography should be first investigation as it is easily available, less expensive, safe and noninvasive method. It excludes those 
adenexal or myometrial pathologies which may be missed in clinical assessment. Hysteroscopy has the additional advantage of its therapeutic value at the same time. Hysteroscopy may be reserved for the cases suspicious of endometrial pathology on ultrasound and all cases of metrorrhagia, menometrorrhagia and postmenopausal bleeding.

Both ultrasonography and hysteroscopy are complementary to each other in case of AUB and simultaneous biopsy confirmed the diagnosis.

\section{REFERENCES}

1. Soules MR, Sherman S, Parrott E. Stages of reproductive aging (STRAW). J Womens Health Gender Based Med 2001;10(9): 843-848.

2. Spiroff L, Fritz MA. Menopause and the perimenopausal transition, clinical endocrinology. In: Spiroff L, Fritz MA, editors. Clinical gynaecology, endocrinology and infertility. 7th ed. Philadelphia. Landon Lippencott Williums and Wilkins; 2005. p. 628.

3. Goldstein SR. The endometrial echo revisited; have we created a monster? Am J Obstet Gynecol 2004;191(4):1092-1096.

4. Goldstein RB, Bree RL, Benson CB. Evaluation of the women with postmenopausal bleeding. J Ultrasound Med 2001;20(10): 1025-1036.

5. Devidson KG, Dubinsky TJ. Ultrasonographic evaluation of the endometrium in postmenopausal vaginal bleeding. Radiol Clin North American 2003 Jul;41(4):769-780.
6. Acharya V, Mehta S, Rander A. Evaluation of dysfunctional uterine bleeding by TVS hysteroscopy and histopathology. J Obstet Gynecol India 2003;53(3):170-177.

7. Bettochi S, Ceci O, Vicino M, et al. Diagnostic inadequacy of dilation and curettage. Fertil Steril 2001 April;74(4):803-805.

8. Saygili H. Histopathological correlation of dilation and curettage and hysterectomy specimens in patients with postmenopausal bleeding. Eur J Gynecol Oncol 2006;27(2):182-184.

9. Machado LS, Mathew M. Corelation of endometrial thickness, cycle day and histopathology in women with AUB. Saudi Med J 2005;26(2):260-263.

10. Albert JR, Hull SK, Weskley RM. Abnormal uterine bleeding. Am Fam Phys 2004;69(8):1915-1926.

11. Aslam A, Gazala. Role of TVS in case of abnormal uterine bleeding. Professional Med J 2009;1(16):127-134.

12. American Cancer Society. The role of transvaginal ultrasonography in the postmenopausal bleeding. ACOG Committee Opinian number 440. American College of Obstetricians and Gynaecologist. Obstet Gynecol 2009 Aug;114(2-Part I):1409-1411.

13. Mandakini P, Anand P. Peri and postmenopausal uterine bleeding transvaginal ultrasound and hysterosonography and diagnostic correlation with hysteroscopy. Donald School J Ultrasound Obstet Gynecol 2012;5(4): 343-352.

14. Jaishwar SP, Sachan R, Srivastava PK. A comparative diagnostic evaluation of hysteroscopy, transvaginal ultrasonography and histopathological examination in case of abnormal uterinebleeding. J Obstet and Gynecol India 2006;56(3):240-243.

15. Archana B, Michelle F. Evaluation and histopathological correlation of abnormal uterine bleeding in perimenopausal women. J Bombay Hospital 2010;52(1):69-72. 